\title{
Effect of repeated learning for two dental CAD software programs
}

\author{
KeunBaDa Son ${ }^{1,2}$, Wan-Sun Lee ${ }^{2}$, Kyu-Bok Lee ${ }^{1,2,3 *}$ \\ 'Department of Dental Science, Graduate School, Kyungpook National University, Daegu, Republic of Korea \\ ${ }^{2}$ Advanced Dental Device Development Institute, Kyungpook National University, Daegu, Republic of Korea \\ ${ }^{3}$ Department of Prosthodontics, School of Dentistry, Kyungpook National University, Daegu, Republic of Korea
}

Purpose: The purpose of this study is to assess the relationship between the time spent designing custom abutments and repeated learning using dental implant computer aided design (CAD) software. Materials and Methods: The design of customized abutments was performed four stages using the 3DS CAD software and the EXO CAD software, and measured repeatedly three times by each stage. Learning effect by repetition was presented with the learning curve, and the significance of the reduction in the total time and the time at each stage spent on designing was evaluated using the Friedman test and the Wilcoxon signed rank test. The difference in the design time between groups was analyzed using the repeated measure two-way ANOVA. Statistical analysis was performed using the SPSS statistics software $(P<0.05)$. Results: Repeated learning of the customized abutment design displayed a significant difference according to the number of repetition and the stage $(P<0.001)$. The difference in the time spent designing was found to be significant $(P<0.001)$, and that between the CAD software programs was also significant $(P=0.006)$. Conclusion: Repeated learning of CAD software shortened the time spent designing. While less design time on average was spent with the 3DS CAD than with the EXO CAD, the EXO CAD showed better results in terms of learning rate according to learning effect. (J Dent Rehabil Appl Sci 2017;33(2):88-96)

Key words: repeated learning; learning curve; CAD software; customized abutment; learning rate

\section{서론}

1980년대 치과용 캐드/캠(Computer Aided Design/ Computer Aided Manufacturing)은 Duret ${ }^{1,2}$ 에 의해 처 음 치과에 도입되었다. 그리고 캐드/캠 기술의 지속적인 개발로 인하여 치과 임상 및 기공의 과정이 디지털 워크 플로우(Digital workflow)로 점차 대체되어가는 과정에 있다. ${ }^{3}$ 치과용 캐드/캠은 Lost Wax Technique 등과 같은 기존의 방법을 벗어나 인레이, 크라운, 임플란트와 같은 고정성 보철 영역과 함께 최근에는 교정 영역과 가철성 보철영역에도 활용되고 있다.

이러한 제작과정에서 캐드(Computer Aided Design)

${ }^{*}$ Correspondence to: Kyu-Bok Lee

Professor, Department of Prosthodontics, School of Dentistry, Advanced

Dental Device Development Institute, Kyungpook National University, 2177

Dalgubuldaero, Jung-gu, Daegu, 41940, Republic of Korea

Tel: +82-53-600-7674, Fax: +82-53-426-7661, E-mail: kblee@knu.ac.kr

Received: May 9, 2017/Last Revision: June 9, 2017/Accepted: June 12, 2017
는 치과 보철물의 설계 분야를 사람의 손으로 직접 하 는 것이 아닌 컴퓨터상의 소프트웨어에서 디자인을 하 는 방법이다. ${ }^{4}$ 최근에는 거의 모든 증례의 치과 보철물 을 캐드 소프트웨어로 디자인할 수 있으며, 그 중에서 도 많이 활용되는 것은 임플란트의 환자 맞춤형 지대주 (Customized Abutment) 디자인이다.

임플란트의 환자 맞춤형 지대주는 1998 년 Lewis ${ }^{5}$ 에 의 해 처음 고안되었고, 캐드/캠에서는 2000년대 초반에 소 개되었다. ${ }^{6}$ 환자 맞춤형 지대주의 장점으로는 상부 보철 물의 형태를 보다 이상적으로 제작하여 파절을 방지하 며, 개개인의 치은 형태에 맞추어 변연 형성이 가능하므 로 잔존 시멘트에 의한 부작용이나 식편압입 등을 예방

Copyright@ 2017 The Korean Academy of Stomatognathic Function and Occlusion. (c) It is identical to Creative Commons Non-Commercial License. 
할 수 있고, 위생관리가 용이하여 임플란트 주위조직 건 강에 유리하다. ${ }^{7-9}$ 이러한 많은 장점과 캐드/캠 기술의 발 달로 임플란트 보철에 있어서 환자 맞춤형 지대주 제작 은 캐드/캠을 이용한 방법으로 점차 변화하고 있다.

캐드 소프트웨어에서 환자 맞춤형 지대주의 제작은 환 자의 증례에 따라서 디자인이 달리 되어야 한다. 이러한 치과용 캐드 소프트웨어를 사용하는데 좀 더 쉽고 편리 하게 사용할 수 있도록 하는 것이 사용 편의성(usability) 에 관한 연구이다. ${ }^{10}$ 1993년 Nielsen ${ }^{11}$ 은 학습능력으로 시 스템을 쉽게 배울 수 있어야 하고, 새로운 시스템을 처음 사용하는 사용자가 그것을 사용하기 위해 학습하는 것 이 사용편의성의 가장 기본적인 속성이라고 하였다. 이러 한 학습을 통하여 동일한 업무를 반복 수행하고 그 작업 이 숙달되었을 때 작업 사이클 당 시간이 짧아지는 능률 증대현상을 ‘학습효과'라고 하며, 그것을 그린 것을 '학습 곡선이라고 한다. ${ }^{12}$ 이 학습 곡선은 의료 및 치과 영역에 새로운 기기를 임상 도입할 때 숙련도를 평가하는 중요 한 기준이 된다.

학습 곡선(Learning Curve)은 1936년 Wright ${ }^{13}$ 에 의해 처음 소개되었고, 항공기의 제조에서 생산량의 증가에 따라 생산 비용이 감소하는 것을 확인하였다. 그리고 이 를 통해 항공기 대당 소요되는 직접 노동이 생산된 비행 기의 누적 대수에 따라 법칙성을 가지고 감소한다는 사 실을 발견하였다. 학습효과가 작업시간에 영향을 미치 는 패턴을 보면 제품의 누적생산량이 두 배가 될 때마다 작업시간은 일정한 양 만큼 감소하는 것을 볼 수 있었다. 예를 들어 누적생산량이 두 배가 될 때마다 약 $20 \%$ 단축 되어 원가가 감소하면 $80 \%$ 의 학습요인이 기인한다는 것 을 알 수 있다. 따라서 이를 보면 학습률(Learning rate) 은 누적 생산량이 두 배가 되면서 발생하는 작업시간의 감소분으로 정의할 수 있다. ${ }^{14}$ 이러한 연구들을 통해 학 습 곡선을 여러 수리적 모델을 이용하여 그래프로 표현 할 수 있고, 작업자의 누적 생산량 당 작업시간을 예측 할 수 있다. ${ }^{10}$ 이러한 학습 곡선은 제조업뿐만 아니라 여 러 산업 분야에서 활용되고 있다. 치과 영역에서 보면 치 과대학 학생들의 교육에서 임상 기술의 반복 학습이 학 생들에게 미치는 영향을 학습 곡선을 통해 연구하였고, 치과 의료기기의 학습에서는 두 종의 디지털 구강 스캐 너를 이용해 구강을 반복적으로 촬영하여 총 촬영시간 과 그 시간의 변화를 학습 곡선 이론을 적용하는 등의 연 구들이 진행되어왔다. ${ }^{15,16}$ 그리고 외과 의료영역에서 반 복 학습을 통한 연구는 작업의 숙련도가 수술의 결과에

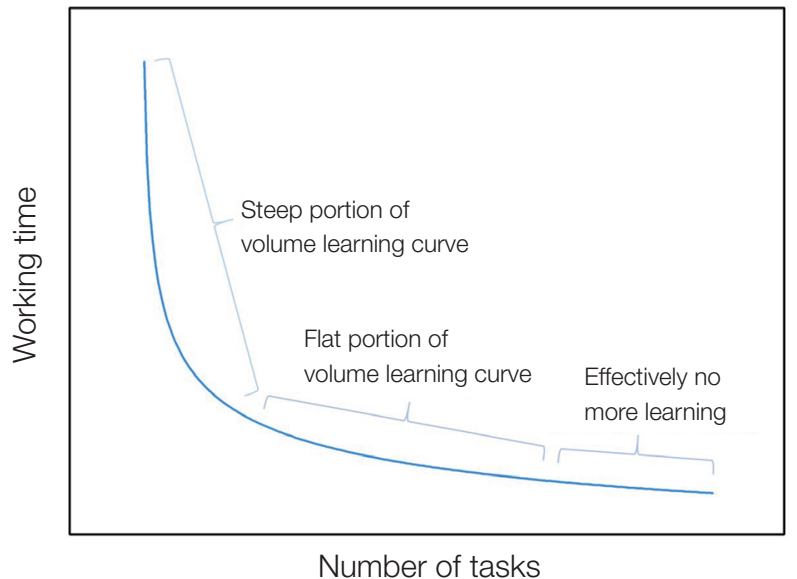

Fig. 1. Graphical illustration of a learning curve with three portion.

많은 영향을 미치고, 이를 반복 학습을 통해 학습 곡선을 상승시키는 방법이 논의되었다. ${ }^{17-20}$ 의료 산업 외에도 에 너지 산업에서는 학습 곡선을 이용하여 미래 비용을 예 측하고, 이를 이용하여 기술의 경쟁력을 효과적으로 평 가하는 데 도움을 주었다(Fig. 1). ${ }^{14,21,22}$

반면 치과 영역에서 실험 연구는 재료 또는 방법의 정 확성 비교나 임플란트를 포함한 보철영역에 편중되어있 고, 치과 임상 및 기공의 과정이 디지털 워크플로우로 대 체되어가고 있는 시점에서 치과용 캐드 소프트웨어를 이 용하는 치과 임상 사용자에 관한 반복 학습에 대해서는 연구가 미미한 실정이다. 특히 치과용 캐드 소프트웨어 의 보철물 디자인에서 술자가 학습을 통하여 어떻게 작 업 시간이 변화하는지에 관한 연구는 현재까지 이루어지 지 않고 있다.

이에 본 연구에서는 컴퓨터상의 캐드 소프트웨어로 임플란트의 환자 맞춤형 지대주를 디자인할 때 소요되 는 시간과 반복 학습의 상관관계를 학습 곡선으로 비 교 평가하였다. 이를 위해 치과용 캐드/캠의 경험이 없 는 치과병원 전공의와 경험이 있는 치과 기공사를 대상 으로 2종류의 캐드 소프트웨어인 3DS 캐드 소프트웨 어(Daesung, Seoul, Korea)와 EXO 캐드 소프트웨어 (Exocad GmbH, Darmstadt, Germany)를 사용하여 두 그룹의 시간 차이를 학습 곡선으로 평가하였다. 


\section{연구 재료 및 방법}

상악 좌측 제 1 대구치 위치에 임플란트가 식립된 석고 모형을 데스크 탑 스캐너(FREEDOM HD, DOF, Seoul, Korea)로 스캔하여 맞춤형 지대주 디자인을 위한 스캔 파일을 준비하였다(Fig. 2). 스캔 파일을 두 대의 동일한 사양의 컴퓨터 본체에 깔린 각 캐드 소프트웨어에 입력 하는 것으로 지대주 디자인을 위한 준비를 마쳤다.

학습자는 치과용 캐드/캠의 경험이 없는 경북대학교 치과병원 보철과 전공의 12 명과 경험이 있는 치과 기공 사 12 명이 선정되었다. 각 소프트웨어에서 설정 가능한
디자인 요소를 바탕으로 맞춤형 지대주의 형태를 정하 였다(Table 1). 두 종의 캐드 소프트웨어인 3DS 캐드 소 프트웨어(Daesung)와 EXO 캐드 소프트웨어(Exocad $\mathrm{GmbH}$ )가 사용되었다(Fig. 3). 학습자는 1시간의 이론교 육을 받았고 맞춤형 지대주 디자인 시연 동영상을 1 회 시 청한 후 평가 직전에 컴퓨터상에서 각 캐드 소프트웨어 당 1 회의 연습을 수행하였다. 학습자들은 두 캐드 소프 트웨어를 사용하여 맞춤형 지대주 디자인을 1단계(프로 그램 실행 및 기본정보 입력), 2 단계(파일 불러오기), 3 단 계(Abutment 디자인 전 조건설정), 4단계(Abutment 디 자인)의 순으로 진행하였고, 기록자들은 학습자의 단계

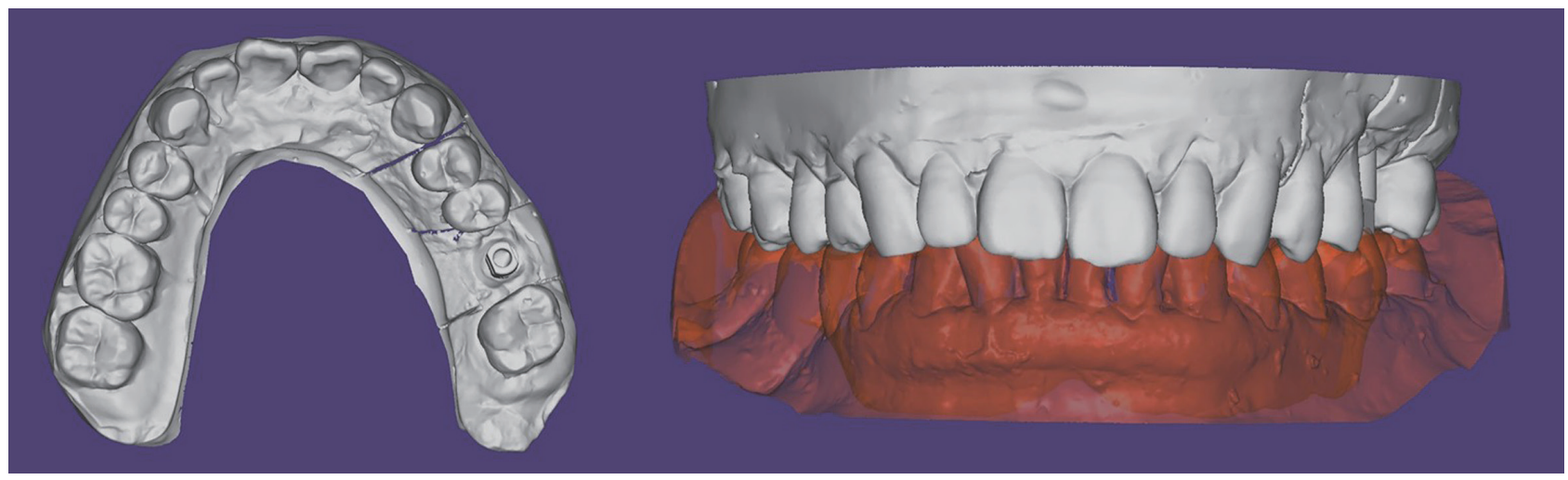

Fig. 2. Dental working models in this study (STL files in EXO CAD software).

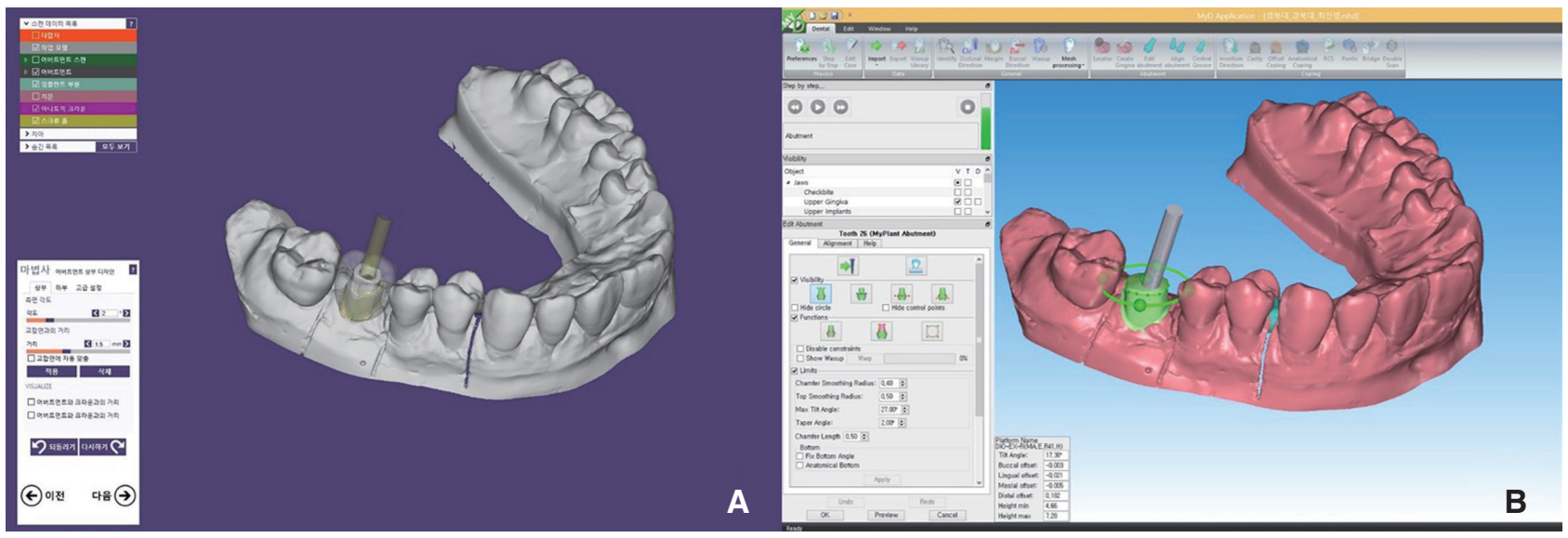

Fig. 3. Dental CAD software in this study. (A) EXO CAD, (B) 3DS CAD.

Table 1. Design conditions of customized abutment

\begin{tabular}{ccc}
\hline & 3DSystem CAD & EXO CAD \\
\hline Scan Body & DIO-EX-R (MA.E.R41.H) & GEO_EXR (Osstem_US_R) implant \\
Abutment angle & $2^{\circ}$ & $4^{\circ}$ \\
Margin line & Equigingival margin \\
\hline
\end{tabular}


별 시간과 최종 디자인의 시간을 초단위로 3 회 반복 측정 하였다. 이때 디자인 통과 기준이 미달된 경우에는 추가 디자인 시간을 포함하여 측정하였다. 캐드 소프트웨어의 학습효과를 파악하기 위하여 반복 학습을 실시하였고 학 습곡선(Learning Curve)은 단계별 시간과 최종 디자인의 소요시간을 바탕으로 작성되었다.

반복 학습에 따라서 소요되는 시간의 감소가 유의한 지는 Friedman test를 이용하여 알아보았다. 그리고 반 복 학습의 횟수에 따른 차이를 보기 위하여 사후검증 (Wilcoxon signed rank test)를 실시하였다. 두 종의 캐 드 소프트웨어의 디자인 시간 차이를 알아보기 위하 여 반복 측정 이 요인 분석(Repeated measure two-way ANOVA)을 진행하였고 차이를 비교하기 위하여 사후검 증(Wilcoxon signed rank test)을 실시하였다. 통계 분석 은 SPSS statistical software for Windows (release 23.0, IBM, Chicago, USA) 을 사용하여 시행하였고 통계적 유 의수준은 0.05 로 검증하였다.

\section{결과}

캐드 소프트웨어로 디자인할 때 학습에 따라서 소요되 는 시간을 측정하고, 학습 곡선으로 나타내었다(Fig. 4). 학습 곡선, Table 2 와 같이 1 회부터 3 회의 반복학습을 통 하여 시간이 줄어들었다.

반복학습에 대한 시간 측정 데이터는 정규분포를 보 이지 않아 Friedman test을 실시하였고, 반복 학습에 따 라 유의한 차이가 나타났다 $(P<0.001)$. 그리고 사후 검정 (Wilcoxon signed rank test)을 통해 1회와 2회 반복 학습 $(P<0.001), 1$ 회와 3 회 반복 학습 $(P<0.001)$ 간에서도 통 계적으로 유의한 차이를 발견하였다 $(\alpha=0.025$, Table 2$)$.

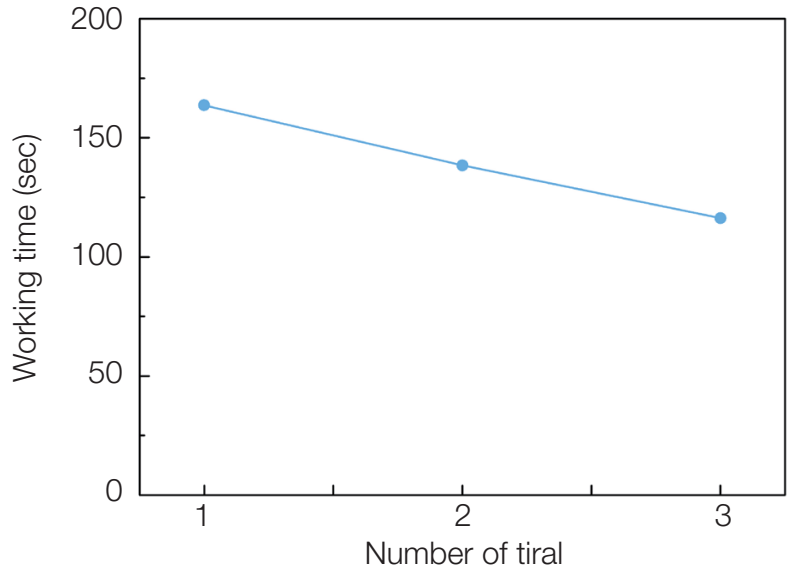

Fig. 4. Learning curve of mean working time for 1 to 3 times of abutment design repeatedly.

두 종의 캐드 소프트웨어에 따라서 환자 맞춤형 지대 주의 디자인을 4단계로 나누었고, 디자인 단계에 따라 서 시간을 측정하였다. 모든 단계에서 1 회부터 3 회의 반 복 학습을 통하여 시간이 줄어들었다. 시간 측정 데이 터는 정규분포를 보이지 않아 3 회의 반복 측정에 대한 Friedman test을 실시하였고, 반복 학습에 따라 차이가 유의하였다 $(P<0.001$, Table 3$)$.

두 종의 캐드 소프트웨어에 따라서 소요되는 시간을 측정하고, 두 개의 학습 곡선으로 나타내었다(Fig. 5). Table 4과 같이 두 종의 캐드 소프트웨어는 모두 1회부 터 3회의 반복 학습을 통하여 시간이 줄어들었다. 그리 고 학습 곡선에서 보면 $\mathrm{EXO}$ 보다 3DS 캐드 소프트웨 어의 작업 시간이 적게 걸려서 곡선이 아래에 위치함을 볼 수 있다. 그러나 학습률(Learning rate)은 3DS보다 $\mathrm{EXO}$ 캐드 소프트웨어가 더 좋은 결과를 보였다. 디자인

Table 2. Comparison of mean working time for 1 to 3 times of abutment design repeatedly (unit: second, $\mathrm{n}=48$ )

\begin{tabular}{cccc}
\hline Group & & 1 to 3 times & Pvalue \\
& & Mean (Standard deviation) & $<0.001^{*}$ \\
\hline \multirow{2}{*}{ Number of Trial } & 1 & $163.66^{\mathrm{a}}(47.56)$ & $<.39^{\mathrm{b}}(40.81)$ \\
& 2 & $116.26^{\mathrm{c}}(27.08)$ & \\
\hline
\end{tabular}

\footnotetext{
* Statistically significant by Friedman test; Different letters indicate significant differences at $P<0.05$.
} 
Table 3. Comparison of mean working time for step-by-step working time of abutment design (unit: second, $\mathrm{n}=48$ )

\begin{tabular}{cccccc}
\hline Group & \multicolumn{1}{c}{ 1 Step } & \multicolumn{2}{c}{$\begin{array}{c}\text { 2 Step } \\
\text { Mean (Standard deviation) }\end{array}$} & 4 Step \\
\hline \multirow{2}{*}{ Number of Trial } & 1 & $29.21(5.83)$ & $12.30(7.34)$ & $79.22(29.61)$ & $25.02(6.78)$ \\
& 2 & $24.37(4.58)$ & $8.12(3.11)$ & $74.58(34.53)$ & $18.71(5.36)$ \\
P-value & 3 & $23.54(4.09)$ & $7.53(2.94)$ & $59.25(22.13)$ & $17.90(3.92)$ \\
\hline
\end{tabular}

* Statistically significant by Friedman test $(P<0.05)$.

Table 4. Comparison of mean working time for EXO and 3DSystem (unit: second, $\mathrm{n}=24$ )

\begin{tabular}{|c|c|c|c|}
\hline \multicolumn{2}{|c|}{ Group } & $\begin{array}{c}\text { 3DSystem } \\
\text { Mean (Standard deviation) }\end{array}$ & $\begin{array}{c}\text { EXO } \\
\text { Mean (Standard deviation) }\end{array}$ \\
\hline \multirow{3}{*}{ Number of Trial } & 1 & $145.80^{\mathrm{a}}(42.84)$ & $181.53^{\mathrm{b}}(46.05)$ \\
\hline & 2 & $125.84^{\mathrm{c}}(40.10)$ & $150.94^{\mathrm{d}}(38.30)$ \\
\hline & 3 & $108.22^{\mathrm{e}}(27.21)$ & $124.30^{\mathrm{f}}(24.96)$ \\
\hline \multirow{4}{*}{$P$ value } & Time & $<0.001 *$ & $<0.001 *$ \\
\hline & Time & \multicolumn{2}{|c|}{$<0.001 * *$} \\
\hline & Group & \multicolumn{2}{|c|}{$0.006^{* *}$} \\
\hline & Time $\times$ Group & \multicolumn{2}{|c|}{$0.178^{* *}$} \\
\hline \multicolumn{2}{|l|}{ Learning rate $(\%)$} & 86.15 & 82.74 \\
\hline
\end{tabular}

* Statistically significant by Friedman test $(P<0.05)$; ** Repeated measure two-way ANOVA $(P<0.05)$.

Different letters indicate significant differences at $P<0.05$.

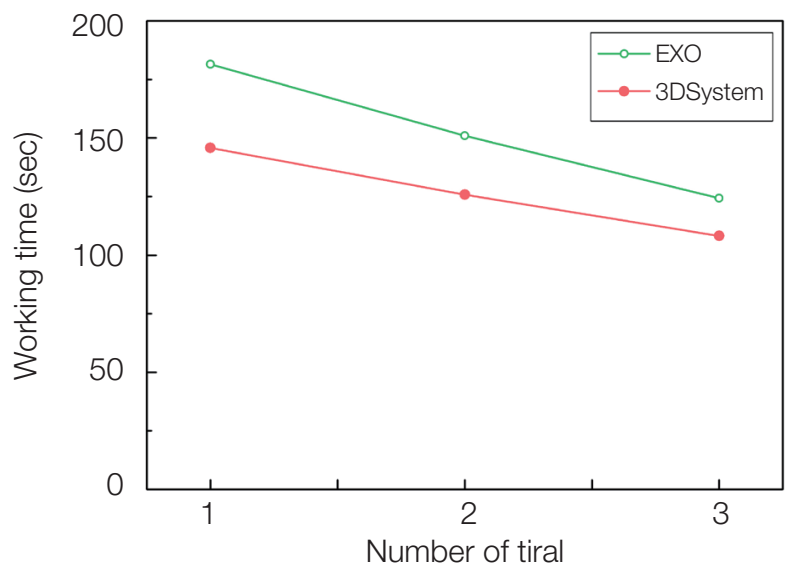

Fig. 5. Learning curve of mean working time for EXO and 3DSystem.
시간 측정 데이터는 정규분포를 보이지 않아 Friedman test을 실시하였고, 반복학습에 따라 차이가 유의하였다 $(P<0.001)$. 그리고 반복 측정 이 요인 분석(Repeated measure two-way ANOVA)에서 시간과 캐드 소프트웨 어는 통계적으로 유의한 상호작용을 보이지 않았다 $(P=$ $0.178)$. 시간에 따른 차이는 유의한 것으로 나타났으며 $(P<0.001)$, 캐드 소프트웨어 간의 차이 역시 유의한 것 으로 나타났다 $(P=0.006)$. 그리고 사후 검정을 통해 1 회 반복 학습에서 $3 \mathrm{DS}$ 와 $\mathrm{EXO}$ 캐드 소프트웨어 간의 통계적으로 유의한 차이를 확인하였으며 $(P=0.008), 2$ 회 반복 학습에서는 임계적으로 유의한 차이가 있었다 $(\alpha$ $\fallingdotseq \mathrm{p})$. 마찬가지로 3 회 반복 학습에서도 유의한 차이 $(P=$ $0.006)$ 를 나타내었다 $(\alpha=0.0166$, Table 4). 


\section{고찰}

본 연구는 치과용 캐드/캠 소프트웨어에 경험이 없는 치과병원 전공의와 경험이 있는 치과 기공사를 대상으로 하여 환자 맞춤형 지대주를 디자인할 때 소요되는 시간 을 반복 측정하였고 치과용 캐드 소프트웨어의 학습 곡 선을 통해 학습 효과를 비교하였다.

Chambers ${ }^{15}$ 는 치과대학 5 개 학과의 학생 465 명을 대 상으로 17 가지 임상 기술을 학습 곡선으로 비교하였고, 학교의 교육과 반복 학습의 관계를 알아보았다. 그리고 $\mathrm{Kim}^{16}$ 의 연구에서는 임상에서 사용되는 디지털 구강스 캐너 두 종의 학습 곡선을 비교하고 학습 효과를 알아보 았다. 이처럼 현재 치과 분야에서의 학습 곡선은 임상에 서 사용되는 기술과 의료기기에서 적용이 되고 있다. 그 러나 디지털 워크플로우로 대체되어가고 있는 시점에서 컴퓨터 소프트웨어를 이용하는 치과 임상 사용자에 관한 반복 학습에 대해서는 연구가 미미한 실정이다.

치과 임상 경력자 중에서도 캐드/캠의 경험이 없는 치 과병원 전공의 12 명과 경험이 1 년 이상인 치과 기공사 12 명을 대상으로 평가하였다. Ospina ${ }^{19}$ 의 연구에서는 4 명 의 외과 전공의를 대상으로 마취 과정에 따라 학습 곡선 을 적용하였다. 그리고 Gonzalez ${ }^{18}$ 는 5명의 외과 전임의 를 대상으로 수술 과정에 관한 학습 곡선을 학습 전후에 서 비교하였다. 본 연구에서는 캐드 소프트웨어의 경험이 없는 치과병원 전공의에서 처음 사용자의 시간과 치과 기 공사에서 경험자의 시간을 비교하여 모집군에 대한 학습 곡선을 알아보았다.

반복 학습을 통해 학습자에게서 학습이 이루어졌으며, 사용의 숙련도가 높아져서 시간이 단축되었다. 본 연구 에서는 캐드 소프트웨어를 이용한 환자 맞춤형 지대주 의 디자인을 1 회부터 3 회의 반복 학습을 하였고, 통계적 으로 유의한 차이에 의해서 시간이 단축되었다. 이는 반 복 학습을 통해 숙련도가 상승하게 되었고, 시간이 단축 되는 학습 효과가 나왔다. Simpson ${ }^{17}$ 은 외과에서 특수한 수술에서는 임상적 경험으로 학습 곡선을 개선하기 어렵 고, 임상 시험을 통해서 학습 곡선을 개선해야 한다고 했 다. 학습곡선의 그래프에서 보면 학습의 효과가 없어 정 체되는 구간까지 임상 시험을 통해 반복 학습을 하고 환 자에게 시술을 해야 한다고 하였다. Jirapinyo ${ }^{23}$ 의 연구에 서는 20 명의 내시경 처음 사용자를 임상 시험하여 내시 경 작업을 반복 학습하였다. 이 연구에서도 마찬가지로 반복 학습을 거듭할수록 학습 곡선은 개선이 되었다.
서로 다른 그룹에서 다른 학습 곡선이 나오고 이에 따 른 학습 효과와 학습률은 그룹에 따라 다르게 나온다. 본 연구에서는 두 종의 캐드 소프트웨어에 따라서 소요 되는 시간을 측정하였고, 두 개의 학습 곡선으로 나타내 었다. 두 종 모두 반복 학습 때문에 숙련도가 상승하게 되었고, 통계적으로 시간이 유의하게 줄어들었다. 그러 나 반복 학습에 따라 두 종의 소프트웨어의 디자인 시간 은 서로 다르게 나왔고, 학습 효과와 학습률도 방법에 따 라 다르게 나왔다. 반복 학습에 따른 디자인 평균시간은 $3 \mathrm{DS}$ 가 $\mathrm{EXO}$ 보다 더 적게 소요되었으나, 학습효과에 따 른 학습률은 $\mathrm{EXO}$ 가 $3 \mathrm{DS}$ 보다 좋게 나왔다. 이는 장기적 인 반복 학습이 계속된다면 시간 감소 폭의 차이로 $3 \mathrm{DS}$ 보다 $\mathrm{EXO}$ 가 더 적은 작업 시간이 소요될 것으로 판단된 다. $\mathrm{Arai}^{24}$ 의 연구에서는 6 명의 심장 내과의사가 수행한 312 회의 사례가 분석되었다. 수술 방법의 처음 사용자와 경험자로 나누어 학습 곡선을 비교한 결과, 경험자 그룹 에서의 수술 성공률이 유의하게 높았다.

본 연구의 결과를 보면 두 종의 캐드 소프트웨어에 따 라 디자인의 단계별 시간이 다른 것을 알 수 있다. 이 는 소프트웨어에 따라 디자인의 방법이 다르기 때문이 다. 우선 1단계 프로그램 실행 및 기본정보 입력을 보면 $\mathrm{EXO}$ 에서 더 많은 시간이 소요되었는데, 이는 $\mathrm{EXO}$ 캐 드 소프트웨어가 더욱 환자의 기본정보를 자세히 입력 하도록 되어있기 때문이다. 2 단계 파일 불러오기에서는 $\mathrm{EXO}$ 에서 더 많은 시간이 소요되었는데, 이는 $\mathrm{EXO}$ 는 스캔 파일을 하나씩 열어서 지정해주는 방식이고, 3DS 은 스캔 폴더를 지정해 불러오는 방식으로 $\mathrm{EXO}$ 가 조금 더 시간이 소요되었다. 그리고 3 단계는 지대주 디자인 전 조건설정으로 설정 가능한 조건이 더욱 많아 $3 \mathrm{DS}$ 에서 더 많은 시간이 소요되었다. 마지막으로 4단계에서는 지 대주 디자인으로 보다 진행 과정이 많은 $\mathrm{EXO}$ 에서 더 긴 시간이 소요되었다. 이처럼 캐드 소프트웨어는 제조사의 따라서 디자인 방법에 차이가 있다. 본 연구에서는 그 차 이에 의한 시간 차이를 줄여 주기 위해 정해진 조건 아래 시간이 측정되었다.

본 연구의 한계로는 3 회 반복 학습은 학습 곡선을 그 리기에 충분한 그래프가 나오지 않았다는 것을 지적할 수 있다. 학습곡선의 그래프는 학습초기에는 급격한 경 사(Steep portion)로 내려가다가 점차 숙련도가 상승하 면서 완만한(Flat portion) 구간으로 변화하고, 결국은 학 습의 효과가 나타나지 않는 구간으로 내려가게 된다(Fig. 1). 이러한 학습 곡선은 본 연구에서는 보이지 않았다. 따 
라서 이런 일반적인 학습곡선을 위해서 많은 반복 학습 이 필요하다고 판단된다.

\section{결론}

치과용 캐드/캠의 디자인 소프트웨어 경험이 없는 치 과병원 전공의와 1 년 이상의 경험이 있는 치과 기공사를 대상으로 하여 환자 맞춤형 지대주를 디자인할 때 소요 되는 시간과 반복 학습의 관계를 학습 곡선을 이용하여 평가하였으며, 그에 따른 결론은 다음과 같다.

1. 반복 학습에 따른 디자인 평균시간은 $3 \mathrm{DS}$ 이 $\mathrm{EXO}$ 에 비하여 더 적은 작업 시간이 소요되었으나, 학습 효과에 따른 학습률은 시간 감소 폭의 차이로 $\mathrm{EXO}$ 가 $3 \mathrm{DS}$ 보다 좋은 결과가 나왔다.

2. 캐드 소프트웨어에서 디자인의 반복 학습을 통해 학 습자에게서 학습이 이루어졌으며, 사용의 숙련도가 높아져서 시간이 단축되었다.

\section{Acknowledgments}

이 논문은 2016년도 정부(미래창조과학부)의 재원으 로 정보통신기술진흥센터의 지원을 받아 수행 된 연구이 며(과제번호: B0101-16-1081, ICT 기반의 의료용 3D 프 린팅 응용 S/W 플랫폼 및 서비스 기술개발), 또한 2017 년도 산업통상자원부 및 산업기술평가관리원(KEIT) 연 구비 지원에 의한 연구임(과제번호: 10062635).

\section{ORCID}

KeunBaDa Son http://orcid.org/0000-0002-3177-8005 Wan-Sun Lee http://orcid.org/0000-0002-4410-5854

Kyu-Bok Lee http://orcid.org/0000-0002-1838-7229

\section{References}

1. Duret F, Preston JD. CAD/CAM imaging in dentistry. Curr Opin Dent 1991;1:150-4.

2. Duret F, Blouin JL, Duret B. CAD-CAM in dentistry. J Am Dent Assoc 1988;117:715-20.

3. Park JH, Kim JE, Shim JS. Digital workflow for a dental prosthesis that considers lateral mandibular relation. J Prosthet Dent 2017;117:340-4.

4. Lee JJ. Relationship of dental stone properties and margins setting in CAD system. Available from: http://www.riss.kr/search/detail/DetailView.do?p _mat_type $=$ be54d9b8bc7cdb09\&control_no $=3 \mathrm{a}$ 8f324dac3261eaffe0bdc3ef48d419 (updated 2017 May 9).

5. Lewis S, Beumer J 3rd, Hornburg W, Moy P. The" UCLA" abutment. Int J Oral Maxillofac Implants 1988;3:183-9.

6. Duke ES. The status of CAD/CAM in restorative dentistry. Compend Contin Educ Dent 2001;22: 968-72.

7. Kim HE, Cho IH. Stress analysis and fatigue failure of prefabricated and customized abutments of dental implants. J Dent Rehabil Appl Sci 2013;29:209-23.

8. Rieder CE. Customized implant abutment copings to achieve biologic, mechanical, and esthetic objectives. Int J Periodontics Restorative Dent 1996;16:20-9.

9. Heydecke G, Sierraalta M, Razzoog ME. Evolution and use of aluminum oxide single-tooth implant abutments: a short review and presentation of two cases. Int J Prosthodont 2002;15:488-93.

10. Hong JI. A study on user's learn ability evaluation method using learning curve model. Graduate School of Korea University of Technology and Education, Master's Thesis; 2007.

11. Nielsen J, Landauer TK. A mathematical model of the finding of usability problems. in Proceedings of the INTERACT'93 and CHI'93 conference on Human factors in computing systems; 1993.

12. Hwang H. Work management. Seoul; Youngji munhwhasa; 1987. p.203-7.

13. Wright TP. Factors affecting the cost of airplanes. J Aeronaut Sci 1936;3:122-8.

14. Kahouli-Brahmi S. Technological learning in energy-environment-economy modelling: a survey. Energy Policy 2008;36:138-62.

15. Chambers D. Learning curves: what do dental students learn from repeated practice of clinical procedures? J Dent Educ 2012;76:291-302.

16. Kim J. Comparison of learning curves between two different intraoral scanners. Available from: http:// www.riss.kr/search/detail/DetailView.do?p_mat_ type $=$ be $54 \mathrm{~d} 9 \mathrm{~b} 8 \mathrm{bc} 7 \mathrm{cdb} 09 \&$ control_no $=22 \mathrm{db} 71188$ 
64f83fdffe0bdc3ef48d419 (updated 2017 May 9).

17. Simpson AH, Howie CR, Norrie J. Surgical trial design - learning curve and surgeon volume: determining whether inferior results are due to the procedure itself, or delivery of the procedure by the surgeon. Bone Joint Res 2017;6:194-5.

18. Gonzalez JM, Cohen J, Gromski MA, Saito K, Loundou A, Matthe K. Learning curve for endoscopic ultrasound-guided fine-needle aspiration (EUS-FNA) of pancreatic lesions in a novel ex-vivo simulation model. Endosc Int Open 2016;4:E128691.

19. Ospina ODA, Medina ÁMR, Marulanda MC, Buitrago LMG. Cumulative Sum learning curves (CUSUM) in basic anaesthesia procedures. Rev Colomb Anestesiol 2014;42:142-53.

20. Khan N, Abboudi H, Khan MS, Dasgupta P, Ahmed K. Measuring the surgical 'learning curve': methods, variables and competency. BJU Int 2014; 113:504-8.

21. Berglund C, Söderholm P. Modeling technical change in energy system analysis: analyzing the introduction of learning-by-doing in bottom-up energy models. Energy Policy 2006;34:1344-56.

22. Ray LaHood, Lisa P. Jackson. Final rule making for 2017-2025 light-duty vehicle greenhouse gas emission standards and corporate average fuel economy standards. EPA and NHTSA 2012;3-24.

23. Jirapinyo P, Abidi WM, Aihara H, Zaki T, Tsay C, Imaeda AB, Thompson CC. Preclinical endoscopic training using a part-task simulator: learning curve assessment and determination of threshold score for advancement to clinical endoscopy. Surg Endosc 2017 Feb 22. doi: 10.1007/s00464-0175436-x. [Epub ahead of print]

24. Arai T, Lefèvre T, Hovasse T, Hayashida K, Watanabe Y, O’Connor SA, Benamer H, Garot P, Cormier B, Bouvier E, Morice MC, Chevalier B. Evaluation of the learning curve for transcatheter aortic valve implantation via the transfemoral approach. Int J Cardiol 2016;203:491-7. 


\section{두 종의 치과용 캐드 소프트웨어에 대한 반복학습의 효과}

손큰바다 ${ }^{1,2}$, 이완선 ${ }^{2}$, 이규복 ${ }^{1,2,3 *}$

${ }^{1}$ 경북대학교 대학원 치의과학과

${ }^{2}$ 경북대학교 첨단치과의료기기개발연구소

${ }^{3}$ 경북대학교 치과대학 치과보철학교실

목적: 치과 임플란트 캐드 소프트웨어를 이용하여 맞춤형 지대주 디자인 시에 소요되는 시간과 반복학습의 관계를 평가 하는 것이다.

연구 재료 및 방법: 맞춤형 지대주 디자인은 3DS 캐드 소프트웨어와 EXO 캐드 소프트웨어를 사용하여 지정된 4개의 단계 순으로 시행되었고, 단계별로 3 회 반복 측정하였다. 반복학습에 의한 학습효과는 학습곡선으로 나타냈고, 반복 학습에 따른 디자인 시에 소요되는 총 시간과 단계별 소요되는 시간의 감소가 유의한지는 Friedman 검정과 사후검증 (Wilcoxon signed rank test)으로 평가하였다. 디자인 시간과 군간의 차이는 반복 측정 이 요인 분석으로 평가하였다. 통 계 분석은 SPSS 통계 소프트웨어를 사용하여 수행하였다 $(P<0.05)$.

결과: 맞춤형 지대주 디자인의 반복학습은 횟수와 단계에 따라 유의한 차이를 나타냈다 $(P<0.001)$. 디자인 시간에 따른 차이는 유의한 것으로 나타났으며 $(P<0.001)$, 캐드 소프트웨어 간의 차이도 유의한 것으로 나타났다 $(P=0.006)$.

결론: 캐드 소프트웨어의 반복학습은 디자인 시간을 단축하였고 디자인 평균시간은 $3 \mathrm{DS}$ 캐드가 $\mathrm{EXO}$ 캐드에 비하여 더 적게 소요되었으나, 학습효과에 따른 학습률은 $\mathrm{EXO}$ 캐드가 3DS 캐드보다 좋은 결과를 보였다.

(구강회복응용과학지 2017;33(2):88-96)

주요어: 반복학습; 학습곡선; 캐드 소프트웨어; 맞춤형 지대주; 학습률 